\title{
El trasplante de células de la glía envolvente del bulbo olfatorio tras lesión de la médula espinal: Estudio experimental en ratas
}

\author{
G. García-Alíasa, R. López-Valesa, E. Verdúa, X. Navarroa, S. Suso y J. Forés ${ }^{a, b}$ \\ ${ }^{a} G r u p o$ de Neuroplasticidad y Regeneración. Universidad Autónoma de Barcelona. Instituto de Neurociencias. Departamentos de Biología \\ Celular, Fisiología e Inmunología. Facultad de Medicina. Bellaterra. 'Instituto del Aparato Locomotor. Universidad de Barcelona. \\ Unidad de la mano y del sistema nervioso periférico. Hospital Clínico y Provincial. Barcelona.
}

Objetivo. Evaluar el efecto a largo plazo del trasplante de células de la glía envolvente (GE) del bulbo olfatorio tras lesión de la médula espinal.

Material y método. Se practicó una laminectomía dorsal T8, en 16 ratas adultas Sprague-Dawley, dejando al descubierto la médula espinal subyacente, la cual se bañó con rosa de Bengala durante 10 minutos, antes de lesionarla por iluminación con una fibra óptica acoplada a una lámpara halógena, durante 2,5 minutos. A la mitad de los animales se les inyectó 180.000 células de GE, en $10 \mu \mathrm{l}$ de medio (grupo GE), y a la otra mitad sólo $10 \mu \mathrm{l}$ de DMEM (Dulbecco's modified Eagle's medium) (grupo DM). Los animales se sacrificaron a los 90 días de efectuar la lesión y se evaluó el área de médula espinal preservada, la recuperación locomotora y la sensibilidad nociceptiva.

Resultados. Los animales del grupo GE mostraron un nivel de locomoción superior y retiraron antes la pata al estímulo nociceptivo que los del grupo DM. También hubo una mayor preservación de parénquima medular y más células p75 positivas en el grupo GE que en el DM.

Conclusiones. El trasplante de GE favorece la preservación de parénquima medular y evita la pérdida de funciones motoras y sensoriales en la rata.

Palabras clave: paraplejía, columna vertebral, algesimetría, glía envolvente, médula espinal.

\section{Transplantation of olfactory bulb ensheathing glia after spinal cord injury: experimental study in rats}

Aim. To evaluate the long-term effect of the transplantation of olfactory bulb ensheathing glia (EG) after spinal cord injury.

Materials and methods. Dorsal laminectomy of T8 was performed in 16 adult Sprague-Dawley rats, exposing the underlying spinal cord, which was bathed with Bengala pink for 10 minutes before producing a lesion by fiberoptic focusing of light from a halogen lamp for 2.5 minutes. Half of the animals were injected 180,000 ensheathing glia (EG) in $10 \mu \mathrm{l}$ of medium (EG group) and half were injected only $10 \mu 1$ of DMEM (Dulbecco's modified Eagle medium) (DM group). Animals were sacrificed 90 days after injury and the area of spinal cord conserved, locomotor recovery, and nociceptive sensitivity were evaluated.

Results. The animals in the EG group showed better locomotion and quicker paw retraction in response to a nociceptive stimulus than the animals in the DM group. More of the spinal parenchyma was preserved and there were more positive p75 cells in the EG group than in the DM group.

Conclusions. EG transplantation favored the preservation of spinal parenchyma and prevented the loss of motor and sensorial functions in the rat.

Key words: paraplegia, spine, algesimetry, ensheathing glia, spinal cord.

\footnotetext{
Correspondencia:

J. Forés Viñeta.

Universidad de Barcelona.

Instituto del Aparato Locomotor.

Unidad de la mano y del sistema nervioso periférico.

Hospital Clínico y Provincial . C/ Villarroel, 170

08036 Barcelona.

Correo electrónico: jfores@ @linic.ub.es

Recibido: octubre de 2003.

Aceptado: octubre de 2004.
}

Premio SECOT Investigación Básica 2003.
La lesión de la médula espinal se caracteriza por una interrupción inmediata e importante de las vías nerviosas ascendentes y descendentes medulares. A parte del tratamiento farmacológico con agentes antiinflamatorios, como la metilprednisolona, que mitigan los efectos del daño medular secundario $^{1}$, no existe una cura efectiva para las lesiones medulares, lo que deja a los pacientes con unas bajas perspectivas clínicas de solución a su problema. 
García-Alías G, et al. El trasplante de células de la glía envolvente del bulbo olfatorio tras lesión de la médula espinal

Las lesiones medulares experimentales son esenciales para obtener información de los procesos fisiopatológicos que suceden durante la lesión medular y ensayar métodos de reparación de la médula espinal que favorezcan la preservación de tejido medular, disminuyan los efectos de la lesión primaria y secundaria y promuevan la supervivencia, regeneración y reinervación funcional de las neuronas lesionadas. Se han utilizado diferentes modelos experimentales para provocar una lesión medular, como la contusión por la caída de un peso (weight-drop), la compresión por medio de pinzas ocluyentes, la sección y/o hemisección y la lesión fotoquímica ${ }^{2-6}$. Todos ellos se caracterizan por causar disrupción de las membranas celulares, de las vías axonales ascendentes y descendentes y lesiones vasculares.

Las hemorragias y el edema medular conllevan un estado de isquemia-hipoxia y de hipoglucemia en la zona de la lesión, y cambios en los niveles extracelulares de electrolitos, responsables de un bloqueo de la conducción de potenciales de acción por los axones lesionados (shock neurogénico) y la liberación de aminoácidos excitatorios (glutamato) causantes de la excito toxicidad neuronal ${ }^{7}$. También se produce una reactivación de los astrocitos y de la microglía. Los primeros se transforman en células hipertróficas, con robustas prolongaciones citoplasmáticas rellenas de proteína ácida fibrilar de la glía (GFAP) que se acumulan alrededor de la zona de lesión primaria, generando una cicatriz glial, que sella y separa la zona necrótica del resto de sistema nervioso central intacto, y contribuyen a la formación de matriz extracelular, con la síntesis y liberación de proteoglicanos que impiden la elongación axonal, pues causan la retracción de los conos de crecimiento de las neuronas regenerativas supervivientes ${ }^{8}$.

La disrupción vascular favorece la entrada de elementos vasculares, inicialmente de neutrófilos y posteriormente de monocitos que se transformarán en macrófagos. Estas células vasculares sintetizan y liberan un conjunto de citocinas que inducen la reactivación de la microglía residente para limpiar las cavidades císticas de los restos celulares muertos. Realizan su papel mediante la liberación de radicales libres de oxígeno, óxido nítrico y enzimas lisosomales, factores que también pueden causar lesiones en regiones adyacentes intactas ${ }^{7}$.

Los objetivos del presente estudio son determinar si el trasplante de glía envolvente (GE) puede tener un efecto reparador en lesiones de la médula espinal, y evaluar si el trasplante de GE mediante microinyecciones mejora los resultados.

\section{MATERIAL Y MÉTODO}

Todos los procedimientos y protocolos experimentales del presente estudio han sido aprobados por el Comité de ética en experimentación animal y humana de nuestra institución.

\section{Cultivo, purificación y criopreservación de las células gliales}

Las células de la GE se obtuvieron de bulbos olfatorios de ratas Sprague-Dawley adultas (250-300 g). Tras anestesia profunda con pentobarbital sódico (70 mg/kg, i.p.), y bajo condiciones de asepsia se procedió a la decapitación y extracción de los bulbos olfatorios que se recogieron en solución salina balanceada de Hank (HBBS, Sigma) con calcio y magnesio a $0^{\circ} \mathrm{C}$. Bajo campana de flujo laminar se procedió a eliminar las meninges, y seguidamente a la digestión enzimática de los bulbos en una mezcla enzimática de tripsina-colagenasa-ADNa, durante $30-45$ minutos, a $37{ }^{\circ} \mathrm{C}$. Posteriormente se disoció mecánicamente el tejido por medio de una pipeta Pasteur a la que previamente se estrechó su punta. A continuación la suspensión celular se centrifugó (900 rpm, 7 minutos), se eliminó el sobrenadante, y el precipitado celular se resuspendió en medio DF10S, que se sembró en frascos de cultivo $\left(25 \mathrm{~cm}^{2}\right)$ previamente poli-Llisinados, utilizando como medio de cultivo DF10S (DMEM + 10\% suero). El medio de cultivo se cambió cada 3 días. A los 9-10 días se utilizó un medio químicamente definido para expandir las células de la GE9 . Tras la confluencia del cultivo (15 días in vitro), se procedió a levantar las células del frasco mediante el uso de tripsina-EDTA en HBBS sin calcio y magnesio. Tras la centrifugación y eliminación del sobrenadante, se purificaron las células de la GE mediante bolitas magnéticas recubiertas con anticuerpos anti-p75. Las células p75 positivas fueron seleccionadas del resto mediante un imán que retenía las células p75 positivas a las paredes del tubo de ensayo. Posteriormente, tras varios centrifugados, la suspensión celular se incluyó en medio crioprotector y se congeló a $-80{ }^{\circ} \mathrm{C}$ hasta su $\mathrm{uso}^{10}$.

\section{Procedimiento quirúrgico y trasplante celular}

Los animales se anestesiaron con pentobarbital $(60 \mathrm{mg} / \mathrm{kg}$, i.p.) y se fijaron a un sistema estereotáxico. Utilizando un microscopio estereoscópico, y bajo condiciones de asepsia, se practicó una laminectomía dorsal en la vértebra T8, dejando al descubierto la médula espinal subyacente. La médula se bañó con una solución de Rosa de Bengala (RB, $1,5 \%$ en solución salina) durante 10 minutos. El exceso de solución se eliminó con varios baños de solución salina, y la zona bañada se iluminó con una fibra óptica acoplada a una lámpara halógena de $100 \mathrm{~W}$, durante 2,5 minutos, a una intensidad lumínica de $80 \mathrm{kLux}$, controlada por medio de un luxómetro (TES-1332, Electrical Electronic Corp, Taipei, Taiwan). La fibra óptica se colocó a $10 \mathrm{~mm}$ de la superficie dorsal de la médula, y durante todo el tiempo de iluminación la médula espinal estuvo bañada con solución salina para evitar su deshidratación ${ }^{11}$. Tras la lesión medular se procedió al trasplante de 180.000 células de GE en $10 \mu \mathrm{l}$ de DMEM (grupo GE; n=8), o bien al trasplante de sólo $10 \mu \mathrm{l}$ de DMEM (grupo DM; n=8). 
La suspensión celular o el vehículo se inyectaron, bajo microscopio estereoscópico, con una micropipeta de vidrio (diámetro interno de 70-90 $\mu \mathrm{m}$ ) acoplada a una jeringa Hamilton montada en un micromanipulador. Las inyecciones se realizaron muy lentamente en dos puntos de la médula espinal lesionada (rostral y caudal), a una profundidad de 1 $\mathrm{mm}$, en las columnas dorsales de la médula espinal.

Finalmente, se procedió a suturar los planos musculares y cutáneos, y a desinfectar la zona intervenida con povidona iodada. Los animales se mantuvieron en observación hasta que despertaron de la anestesia.

\section{Métodos funcionales}

Las pruebas funcionales se realizaron antes de la operación y, posteriormente, a los 7, 14, 30, 60 y 90 días de la lesión. La capacidad de locomoción de los animales se evaluó colocando al animal en un campo abierto circular $(90 \mathrm{~cm}$ de diámetro $\times 24 \mathrm{~cm}$ de pared) y valorando el movimiento de la extremidades posteriores, por dos observadores independientes, según la escala $\mathrm{BBB}^{12}$, que oscila entre 0 puntos (parálisis completa) hasta 21 puntos (locomoción normal). El resultado final fue el promedio de las anotaciones de ambos observadores.

La sensibilidad nociceptiva se evaluó mediante la prueba de la algesimetría plantar ${ }^{13}$. Los animales se colocaron en una caja transparente alta, cuyo suelo estaba formado por una placa de vidrio, a través de la cual se hacía incidir, sobre la superficie de las patas posteriores del animal, un rayo de luz incandescente que surgía de una lámpara halógena de $150 \mathrm{~W}$. Mediante un detector de infrarrojos, se valoró el tiempo que el animal tardaba en retirar la pata posterior al estímulo nociceptivo. Para evitar lesiones cutáneas se limitó el tiempo máximo de exposición a la luz incandescente a 40 segundos. La prueba se repitió tres veces, con intervalos de descanso de 5 minutos. El valor final fue el promedio de las tres repeticiones.

\section{Métodos inmunohistoquímicos e histomorfométricos}

A los 90 días postoperación los animales fueron anestesiados profundamente y perfundidos transcardiacamente con $4 \%$ de paraformaldehído, en tampón fosfato salino (PBS; 0,1M; pH: 7.4). Posteriormente se extrajo la médula espinal y el segmento medular lesionado fue fijado en la misma solución, durante 24 horas, a $4{ }^{\circ} \mathrm{C}$ e incluido en medio crioprotector ( $30 \%$ de sacarosa en PBS) durante 48 horas a $4{ }^{\circ} \mathrm{C}$. De dicho bloque medular se realizaron secciones transversales seriadas de $30 \mu \mathrm{m}$ de grosor mediante un criostato, que se recogieron en un tampón crioprotector De Olmos y fueron guardadas a $-18{ }^{\circ} \mathrm{C}$ hasta su uso.

Por medio de la técnica de flotación las secciones fueron lavadas con PBS para eliminar el exceso de De Olmos, posteriormente fueron incubadas con $0,3 \%$ de Triton-X-100 y $1 \%$ de suero fetal bovino en PBS, durante 1 hora a $4{ }^{\circ} \mathrm{C}$ y en constante agitación. Finalmente, se incubaron con el anticuerpo primario policlonal de conejo contra la proteína ácida fibrilar de la glía (GFAP; 1:1000; Chemicon ${ }^{\circledR}$ ) y monoclonal de ratón antirreceptor de baja afinidad del factor de crecimiento nervioso (p75; 1:200; Chemicon $^{\circledR}$ ), durante 24 horas a $4{ }^{\circ} \mathrm{C}$, y en agitación. Tras varios lavados con $1 \%$ de suero fetal bovino en PBS, las secciones medulares se incubaron con el anticuerpo secundario IgG de asno anticonejo o antiratón conjugados a la cianina 3,18 (Cy3; 1:200; Jackson Immunoresearch ${ }^{\circledR}$ ) durante toda la noche, a $4{ }^{\circ} \mathrm{C}$, en agitación. Al día siguiente, tras varios lavados con PBS, las secciones se montaron en portaobjetos pregelatinados, se deshidrataron en baños crecientes de etanol $\left(50^{\circ}, 70^{\circ}, 90^{\circ}\right.$, $96^{\circ}$, absoluto) y finalmente el cubreobjetos se montó con DPX (Fluka ${ }^{\circledR}$ ). Como control, algunas secciones fueron incubadas sólo con anticuerpo secundario. Todas las secciones fueron observadas con un microscopio de epifluorescencia (Olympus ${ }^{\circledR}$ BX51) usando filtros apropiados.

Se captaron imágenes completas de las médulas espinales inmunomarcadas para GFAP, que fueron analizadas por medio del software NIH-image (versión 1.62; disponible en http://rbs.info.nih.gov/nih-image; EEUU), para medir el área de médula espinal preservada. Dos investigadores independientes efectuaron dichas mediciones sobre las mismas imágenes capturadas. El área final de médula espinal preservada, de cada sección analizada, fue el promedio del valor obtenido de ambos investigadores. Para cada animal se analizaron entre 8-10 secciones medulares ${ }^{11}$.

\section{Análisis estadístico}

Todas las valoraciones funcionales, electrofisiológicas e histológicas se han realizado a ciegas, mediante el uso de un código tanto en animales como en muestras histológicas. Las comparaciones estadísticas entre grupos se han realizado mediante el análisis de la varianza (ANOVA), usando la prueba de Scheffé para múltiples comparaciones. Se han considerado diferencias significativas cuando $\mathrm{p}<0,05$.

\section{RESULTADOS}

Antes de la operación todos los animales de ambos grupos experimentales mostraron un patrón normal de locomoción, puntuado como 21 en la escala BBB. A los 7 días postoperación, la habilidad locomotora de los animales de ambos grupos experimentales disminuyó, siendo de aproximadamente 14 y 19 puntos en la escala BBB, para los grupos DM y GE, respectivamente. La puntuación de la locomoción fue aumentando progresivamente, alcanzando al final del seguimiento valores de 16 y 20 puntos de la escala $\mathrm{BBB}$ en los grupos DM y GE, respectivamente. A lo largo de todo el seguimiento postoperatorio el grado de locomoción de los animales del grupo GE fue significativamente superior al de los animales del grupo DM (tabla 1). 
García-Alías G, et al. El trasplante de células de la glía envolvente del bulbo olfatorio tras lesión de la médula espinal

Tabla 1. Resultados funcionales en el seguimiento

\begin{tabular}{|c|c|c|c|c|c|}
\hline \multirow{2}{*}{ Prueba } & \multirow{2}{*}{ Días evolución } & \multicolumn{2}{|c|}{ Grupo control } & \multicolumn{2}{|c|}{ Grupo con glía envolvente } \\
\hline & & $\overline{\mathrm{x}}$ & ES & $\overline{\mathrm{x}}$ & ES \\
\hline \multirow[t]{6}{*}{ Locomoción (escala BBB) } & 0 & 21,00 & 0,00 & 21,00 & 0,00 \\
\hline & 7 & 13,62 & 1,14 & $18,81 * *$ & 0,69 \\
\hline & 14 & 17,08 & 0,90 & $19,82 *$ & 0,46 \\
\hline & 30 & 16,75 & 0,77 & $19,94 * *$ & 0,49 \\
\hline & 60 & 16,38 & 0,70 & $20,03 * * *$ & 0,47 \\
\hline & 90 & 16,13 & 0,51 & $20,19 * * *$ & 0,40 \\
\hline \multirow[t]{6}{*}{ Algesimetría (segundos) } & 0 & 15,42 & 0,10 & 15,41 & 0,09 \\
\hline & 7 & 16,64 & 0,30 & $17,42 * *$ & 0,12 \\
\hline & 14 & 17,90 & 0,21 & $16,60 * * *$ & 0,08 \\
\hline & 30 & 18,87 & 0,36 & $16,61 * * *$ & 0,14 \\
\hline & 60 & 18,42 & 0,40 & $16,31 * *$ & 0,17 \\
\hline & 90 & 18,40 & 0,24 & $16,07 * * *$ & 0,15 \\
\hline
\end{tabular}

Xे: media; ES: error estándar de la media; ${ }^{*} \mathrm{p}<0,05 ; * * \mathrm{p}<0,01 ; * * * \mathrm{p}<0,001$ respecto al grupo DM.

El tiempo de retirada de la pata posterior a un estímulo térmico doloroso fue de aproximadamente 15 segundos en todos los animales de ambos grupos experimentales antes de la operación. Tras la lesión medular el tiempo de retirada al estímulo doloroso aumentó en los animales de ambos grupos experimentales, siendo en promedio de aproximadamente 19 y 17 segundos en los grupos DM y GE, respectivamente, a los 7 días postoperación. Entre los 7 y 90 días después de la lesión, hay una tendencia a aumentar ligeramente el tiempo de retirada en los animales del grupo DM, mientras que en los del grupo GE tiende a disminuir. A lo largo del seguimiento, el valor promedio del tiempo de retirada en los animales del grupo DM fue igual o superior a 18 segundos, mientras que en los animales del grupo GE nunca superó los 18 segundos. Durante todo el seguimiento, el tiempo de retirada en los animales del grupo GE fue significativamente inferior al de los animales del grupo DM (tabla 1).

En todos los animales de ambos grupos experimentales la lesión afecta principalmente a la región dorsal de la médula espinal. En los animales del grupo DM, la lesión incluye el funículo dorsal, comprometiendo, en la mayoría de los animales, el tracto córtico-espinal e incluso el canal central. Asimismo, en varios animales de este grupo experimental también se observaron lesionadas las regiones dorsolaterales de la médula espinal. Un patrón similar se encontró en las secciones de los animales del grupo GE, aunque en la mayoría de ellos la lesión se circunscribe casi exclusivamente al funículo dorsal y en alguno se extiende hacia regiones dorso-laterales (figs. 1A-B). El promedio del área de médula espinal preservada fue mayor en el grupo GE que en el DM $\left(3,12 \pm 0,07\right.$ y 2,85 $\pm 0,09 \mathrm{~mm}^{2}$, respectivamente), presentando diferencias significativas entre ambos grupos experimentales $(\mathrm{p}<0,05)$. Cualitativamente, se observaron más células positivas para p75 en las secciones medulares de los animales con trasplante de GE que en los animales con inyección de DMEM (figs. 1C-D).
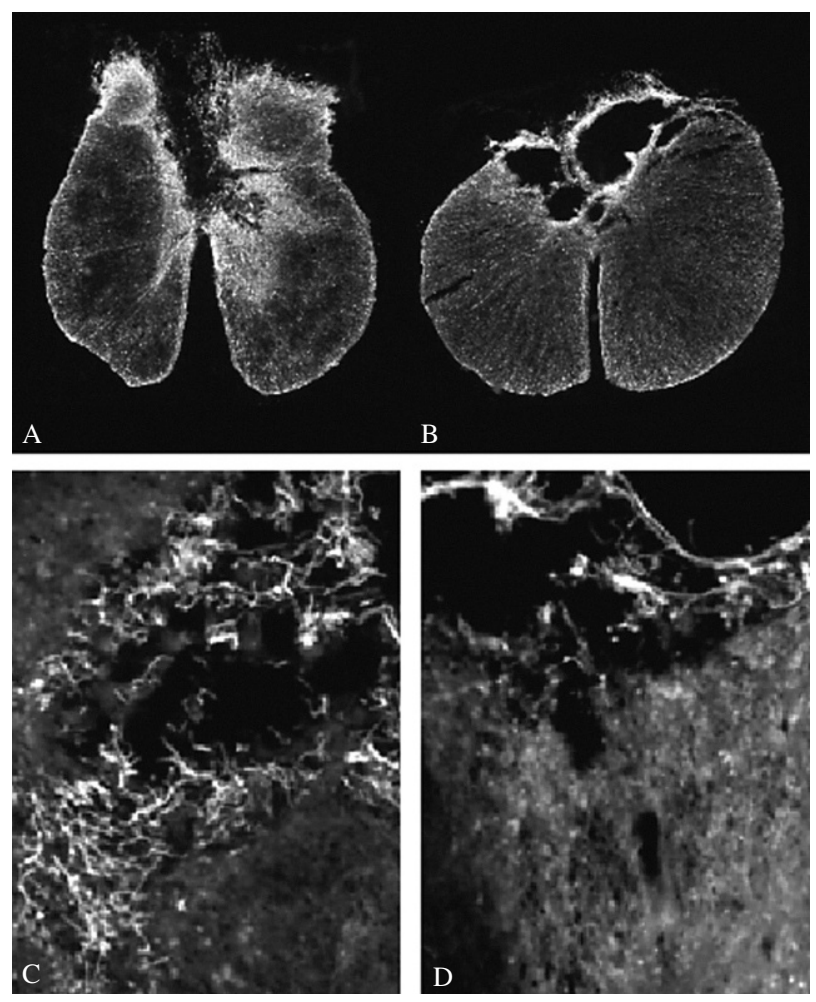

Figura 1. Secciones transversales de la médula espinal inmunomarcadas contra GFAP de las ratas con (A) trasplante de glía envolvente del bulbo olfatorio (X4) y (B) con trasplante de DMEM (x4). Microscopia óptica con epifluorescencia de $(C)$ campos próximos a la zona lesionada (*) de secciones medulares inmunomarcadas para $p 75$ de ratas con trasplante de glía envolvente $(\times 20)$ y $(D)$ con inyección de DMEM (×20). Todas las manchas blancas y filamentosas de las imágenes $C y$ $D$ corresponden a células inmunorreactivas al p75. Nótese que existen más en la imagen correspondiente al grupo GE que al DM.

\section{DISCUSIÓN}

Los resultados del presente estudio demuestran que el trasplante agudo de células de la GE del bulbo olfatorio me- 
diante microinyección con jeringa Hamilton, en una lesión moderada de la médula espinal, evita una pérdida significativa de las funciones motoras y sensoriales. Asimismo, en los animales con trasplante de células gliales, el área de médula espinal preservada es significativamente superior a la de los animales con trasplante de DMEM. Cualitativamente, se observa un mayor número de células positivas a p75 en las secciones medulares del grupo GE que en las del grupo DM. Todos estos resultados son similares a los observados recientemente cuando se trasplanta GE o DMEM mediante micropipetas de vidrio acopladas a un inyector de pulsos de ai$\mathrm{re}^{11,14}$, lo cual sugiere que el método de trasplante celular no es un factor que influya directamente en la recuperación funcional, sino que es la terapia celular la que repercute sobre la preservación de tejido y de las funciones neurológicas.

Una de las ventajas de la terapia mediante trasplante de GE es que sus efectos no se limitan a la zona del trasplante, pues dicha glía tiene una alta capacidad de migración a través de la médula espinal lesionada ${ }^{14,15}$. Los estudios experimentales previos en los que se ha trasplantado GE son contradictorios, pues hay investigadores que indican que en los animales trasplantados existe mayor recuperación funcional respecto a animales sin trasplante o con trasplante de vehículo ${ }^{14,16-18}$, mientras que otros investigadores no obtienen diferencias ${ }^{19}$. Sin embargo, en los animales trasplantados con GE se reduce la cavitación ${ }^{11,14,20}$ y aumenta el número de fibras regenerativas a través de la lesión ${ }^{18,20}$. Estos resultados sugieren que el trasplante GE en lesiones de la médula espinal puede ser beneficioso, reduciendo la extensión de la lesión primaria y/o secundaria, y favoreciendo la regeneración de los axones de las neuronas supervivientes, aunque no se traduce siempre en una mayor recuperación funcional.

Los mecanismos por los cuales las células de la GE del bulbo olfatorio pueden realizar los efectos observados en el presente estudio son múltiples. Diversos estudios in vitro han demostrado que las células de la GE son capaces de sintetizar y liberar al medio de cultivo diversos factores neurotróficos, tales como el factor neurotrófico derivado de la glía (GDNF), el factor neurotrófico derivado del cerebro (BDNF), el factor de crecimiento nervioso $(\mathrm{NGF})^{21}$, y la neurotrofina $4 / 5^{15}$. La supervivencia y regeneración de los axones de las neuronas rubroespinales y corticoespinales es dependiente de $\mathrm{BDNF}^{22,23}$, mientras que la elongación de las neuronas noradrenérgicas del locus ceroleus son dependientes de $\mathrm{GDNF}^{24}$.

Las células de la GE tienen la capacidad de sintetizar y secretar moléculas de la matriz extracelular, como laminina y fibronectina ${ }^{25}$, componentes del parénquima medular que favorecen la elongación de las neuritas in vitro ${ }^{26}$ y constituyen el sustrato sobre el que pueden elongarse los axones regenerativos que siempre buscan rodear las cavidades císticas que se generan tras una lesión medular.

A pesar de que no existen estudios experimentales que demuestren que las células de GE trasplantadas sigan sinteti- zando y liberando factores tróficos y trópicos, tampoco existen estudios que demuestren lo contrario, por lo que potencialmente las células trasplantadas in vivo siguen manteniendo las mismas propiedades que in vitro, y ello hace pensar que las células de GE son capaces de promover la supervivencia y regeneración de axones espinales. Los tipos axonales anteriormente citados participan directamente en el control motor y en la locomoción de la rata, y se ha demostrado la regeneración de axones espinales, a través de la lesión, en animales que habían recibido un trasplante de $\mathrm{GE}^{17,18,27}$.

Un segundo factor es que la GE trasplantada pueda facilitar una mayor migración de células promotoras de la regeneración, tales como las células de Schwann del sistema nervioso periférico. Tras una lesión medular sin reparación se produce, a los pocos días de la lesión, una entrada de células de Schwann desde la periferia, que invaden el parénquima medular, localizándose en las proximidades de las cavidades císticas y que pueden contribuir a la supervivencia y regeneración de los axones lesionados. De hecho, se ha comprobado que injertos de nervios periféricos ${ }^{28} \mathrm{o}$ implantes de cámaras tubulares rellenas con células de Schwann ${ }^{29,30}$ promueven la regeneración de los axones centrales por el interior de dichos implantes, lo cual se atribuye al conjunto de factores neurotróficos secretados por las células de Schwann implantadas. Tanto la célula de la GE como la célula de Schwann son positivas para $\mathrm{p} 75^{25}$, por lo que la presencia de células p75 en las secciones medulares de ambos grupos experimentales no nos permite discernir si todas ellas son de un solo tipo, ni de qué tipo son. Sin embargo, cualitativamente detectamos más células p75 positivas en las secciones histológicas de los animales con trasplante de GE que en las de los animales con DMEM, lo que sugiere que la GE trasplantada puede favorecer la migración de células de Schwann, las cuales también contribuyen a generar un microambiente favorecedor de supervivencia y/o elongación de los axones espinales lesionados.

En resumen, el presente estudio confirma que el trasplante de GE del bulbo olfatorio promueve, directa o indirectamente, una mayor preservación de tejido medular, lo que puede facilitar la regeneración de axones espinales supervivientes y mantener una mayor respuesta motora y sensorial. La inyección de la GE mediante micropipeta acoplada a una jeringa Hamilton no ofrece resultados funcionales e histológicos diferentes a los observados cuando estas células son trasplantadas mediante micropipeta acoplada a un impulsor de aire ${ }^{11,14}$. Aunque su aplicación clínica requiere de más experimentos que permitan dilucidar algunos de los aspectos reseñados.

\section{AGRADECIMIENTOS}

Los autores agradecen a Mónica Espejo su ayuda técnica. El presente trabajo ha sido financiado por los proyectos 
García-Alías G, et al. El trasplante de células de la glía envolvente del bulbo olfatorio tras lesión de la médula espinal

de investigación del Ministerio de Sanidad y Consumo (FISS 00/0031-02) y del Ministerio de Ciencia y Tecnología (SAF2002-04016-C02-02) de España, y por fondos FEDER de la Unión Europea.

\section{BIBLIOGRAFÍA}

1. Amar AP, Levy ML. Pathogenesis and pharmacological strategies for mitigating secondary damage in acute spinal cord injury. Neurosurg. 1999;44:1027-40.

2. Allen AR. Surgery of experimental lesions of spinal cord equivalent to crush injury of fracture dislocation of spinal column. A preliminary report. J Am Med Assoc. 1911;57:87880.

3. Basso DM, Beattie MS, Bresnahan JC. Graded histological and locomotor outcomes after spinal cord contusion using the NYU weight-drop device versus transection. Exp Neurol. 1996; 139:244-56.

4. Prado R, Dietrich WD, Watson BD, Ginsberg MD, Green BA. Photochemically induced graded spinal cord infarction. J Neurosurg. 1987;67:745-53.

5. Rivlin AS, Tator $\mathrm{CH}$. Effect of duration of acute spinal cord compression in a new acute model in the rat. Surg Neurol. 1978; 10:38-43.

6. Verdú E, García-Alías G, Forés J, Vela JM, Cuadras J, López-Vales R, et al. Morphological characterization of photochemical graded spinal cord injury in the rat. J Neurotrauma 2003;20:483-99.

7. Schwab ME, Bartholdi D. Degeneration and regeneration of axons in the lesioned spinal cord. Physiol Rev. 1996;76:31970.

8. Bovolenta P, Fernaud-Espinosa I, Méndez-Otero R, NietoSampedro M. Neurite Outgrowth inhibitor of gliotic brain tissue. Mode of action and cellular localization, studied with specific monoclonal antibodies. Eur J Neurosci. 1997;9:977-89.

9. Gudiño-Cabrera G, Nieto-Sampedro M. Schwann-like macroglia in adult rat brain. Glia. 2000;30:49-63.

10. Gudiño-Cabrera G, Nieto-Sampedro M. Ensheathing cells: large scale purification from adult olfactory bulb, freeze-preservation and migration of transplanted cells in adult brain. Restor Neurol Neurosci. 1996;10:25-34.

11. Verdú E, García-Alías G, Forés J, López-Vales R, Navarro X. Olfactory ensheathing cells transplanted in lesioned spinal cord prevent loss of spinal cord parenchyma and promote functional recovery. Glia. 2003;42:275-86.

12. Basso DM, Beattie MS, Bresnahan JC. A sensitive and reliable locomotor rating scale for open field testing in rats. J Neurotrauma. 1995; 12:1-21.

13. Hargreaves K, Dubner R, Brown F, Flores C, Joris J. A new and sensitive method for measuring thermal nociception in cutaneous hyperalgesia. Pain. 1988;32:77-88.

14. Verdú E, García-Alías G, Forés J, Gudiño-Cabrera G, Muñetón VC, Nieto-Sampedro M, et al. Effects of ensheathing cells transplanted into photochemically damaged spinal cord. Neuroreport. 2001;12:2303-9.

15. Boruch AV, Conners JJ, Pipitone M, Deadwyler G, Storer PD, Devries GH, et al. Neurotrophic and migratory properties of an olfactory ensheathing cell line. Glia. 2001;33:225-9.

16. Imaizumi T, Lankford KL, Kocsis JD. Transplantation of olfactory ensheathing cells or Schwann cells restores rapid and secure conduction across the transected spinal cord. Brain Res. 2000;854:70-8.
17. Lu J, Féron F, Mackay-Sim A, Waite PME. Olfactory ensheathing cells promote locomotor recovery after delayed transplantation into transected spinal cord. Brain. 2002;125:14-21.

18. Ramón-Cueto A, Cordero MI, Santos-Benito FF, Ávila J. Functional recovery of paraplegic rats and motor axon regeneration in their spinal cords by olfactory ensheathing glia. Neuron. 2000;25:425-35.

19. Takami T, Oudega M, Bates ML, Wood PM, Kleitman N, Bunge MB. Schwann cells but not olfactory ensheathing glia transplants improve hindlimb locomotor performance in the moderately contused adult rat thoracic spinal cord. J Neurosci. 2002;22:6670-81.

20. Plant GW, Christensen CL, Oudega M, Bunge MB. Delayed transplantation of olfactory ensheathing glia promotes sparing/regeneration of supraspinal axons in the contused adult rat spinal cord. J Neurotrauma. 2003;20:1-16.

21. Woodhall E, West AK, Chuah MI. Cultured olfactory ensheathing cells express nerve growth factor, brain-derived neurotrophic factor, glia cell line-derived neurotrophic factor and their receptors. Mol Brain Res. 2001;88:203-13.

22. Liu Y, Kim D, Himes BT, Chow SY, Schallert T, Murray M, et al. Transplants of fibroblasts genetically modified to express BDNF promote regeneration of adult rat rubrospinal axons and recovery of forelimb function. J Neurosci. 1999; 19:4370-87

23. Lu P, Blesch A, Tuszynski MH. Neurotrophism without neurotropism: BDNF promotes survival but not growth of lesioned corticospinal neurons. J Comp Neurol. 2001;436:456-70.

24. Holm PC, Akerud P, Wagner J, Arenas E. Neurturin is a neuritogenic but not a survival factor for developing and adult central noradrenergic neurons. J Neurochem. 2002;81:1318-27.

25. Ramón-Cueto A, Avila J. Olfactory ensheathing glia: properties and function. Brain Res Bull. 1998;46:175-87.

26. Snow DM, Smith JD, Gurwell JA. Binding characteristics of chondroitin sulfate proteoglycans and laminin-1, and correlative neurite outgrowth behaviors in a standard tissue culture choice assay. J Neurobiol. 2002;51:285-301.

27. Nash HN, Borke RC, Anders JJ. Ensheathing cells and methylprednisolone promote axonal regeneration and functional recovery in the lesioned adult rat spinal cord. J Neurosci. 2002;22:7111-20.

28. Richardson PM, McGuinness UM, Aguayo AJ. Axons from CNS neurons regenerate into PNS grafts. Nature. 1980;20: 264-5.

29. Guest JD, Rao A, Olson L, Bunge MB, Bunge RP. The ability of human Schwann cell grafts to promote regeneration in the transected nude rat spinal cord. Exp Neurol. 1997;148: 502-22.

30. Ramón-Cueto A, Plant GW, Avila J, Bunge MB. Long-distance axonal regeneration in the transected adult rat spinal cord is promoted by olfactory ensheathing glia transplants. J Neurosci. 1998;18:3803-15.

Conflicto de intereses. Los autores no hemos recibido ayuda económica alguna para la realización de este trabajo. Tampoco hemos firmado ningún acuerdo por el que vayamos a recibir beneficios $u$ honorarios por parte de alguna entidad comercial. Por otra parte, ninguna entidad comercial ha pagado ni pagará a fundaciones, instituciones educativas $\mathrm{u}$ otras organizaciones sin ánimo de lucro a las que estemos afiliados. 